\title{
Reliability of two different bedside assays for C-reactive protein in newborn infants
}

\author{
Enrico Zecca*, Giovanni Barone, Mirta \\ Corsello, Costantino Romagnoli, Eloisa Tiberi, \\ Chiara Tirone and Giovanni Vento \\ Division of Neonatology, Department of Pediatrics, \\ Catholic University of the Sacred Heart, Rome, Italy
}

\begin{abstract}
Background: Bedside tests for C-reactive protein (CRP) have been studied in pediatric patients, but not in neonates.

Methods: This study compared the results of two rapid bedside tests for CRP (Quick-Read CRP, Orion Diagnostic, Espoo, Finland and NycoCard CRP-Single Test, Axis-Shield, Oslo, Norway) with those of our central laboratory method (CRP-Lab) in newborn infants. CRP concentrations were determined using 72 samples obtained from 43 infants with suspected sepsis occurring between 1 and 28 days of life.

Results: Considering positive CRP concentrations to be $\geq 10 \mathrm{mg} / \mathrm{L}$, both bedside tests had good specificity (Quick-Read 80.5\%, NycoCard 83.3\%) and sensitivity (Quick-Read 97.2\%, NycoCard 94.4\%) when compared with our CRP-Lab. The agreement of measurement with central laboratory values was high for both the bedside tests, without statistically significant differences between the methods. The Quick-Read and NycoCard methods did not show any statistically significant systematic proportional bias when compared with the central laboratory values. The accuracy of the results of both bedside tests is somewhat decreased when CRP concentrations are $>100 \mathrm{mg} / \mathrm{L}$.

Conclusions: This study shows that both the QuickRead and the NycoCard test can be used for serial determinations of CRP concentrations in newborn infants. They require small volumes of blood and provide reliable results in $<5 \mathrm{~min}$.

Clin Chem Lab Med 2009;47:1081-4.
\end{abstract}

Keywords: bedside testing; C-reactive protein; newborn infant; sensitivity and specificity; sepsis.

\section{Introduction}

Neonatal sepsis is a systemic disease, characterized by massive microbial invasion followed by a systemic

*Corresponding author: Dr. Enrico Zecca, Division of Neonatology, Department of Pediatrics, Catholic University of the Sacred Heart, Largo Agostino Gemelli 8, 00168 Rome, Italy

Phone: +39630154169, Fax: +3963383211,

E-mail: enrizecca@rm.unicatt.it

Received February 20, 2009; accepted June 2, 2009 inflammatory response (1-3). It affects $15 \%-30 \%$ of newborn infants admitted to the neonatal intensive care unit, particularly very low birth weight infants, with high mortality (2). Because the suspicion of sepsis in the neonate is often based on non-specific clinical signs, several predictive laboratory parameters have been investigated, including white blood cell count, tumor necrosis factor, interleukin-6, serum amyloid $A$, procalcitonin and $C$-reactive protein (CRP) (4-8). Serial CRP measurements are also used to monitor the evolution of bacterial diseases because CRP concentration drops quickly in response to effective treatment (9). Monitoring CRP concentration can lead to shorter antibiotic regimens or, alternatively, can alert one to the likelihood of complications and help predict outcome, even earlier than clinical signs (10). Conventional laboratory methods for CRP can be unavailable in urgent situations, or may not provide results in a timely manner. They usually require at least $1 \mathrm{~mL}$ of blood and are uncomfortable if used for serial measurements in newborn infants. Rapid bedside quantitative assays for CRP that require insignificant amount of blood have been developed recently. Unfortunately, no data has been published about their use in the neonatal period, apart from the short report by Makhoul and coworkers on late-onset sepsis (11). The aim of this study was to compare the diagnostic accuracy between two rapid bedside tests for CRP compared with the laboratory method, and provide information about their reliability in newborn infants.

\section{Materials and methods}

\section{Study population}

This prospective observational study was conducted from March to September 2008, in the Division of Neonatology at our University Hospital. The study was approved by our Institutional Ethical Board. We included all newborns who developed clinically suspected sepsis during the first month of life. Infants were confined to open cots or incubators, depending on their weight. For each infant we collected gestational age, birth weight, age and weight when sepsis was first suspected, hematocrit and CRP values. Work-up for sepsis included blood, urine and cerebrospinal fluid cultures for all infants. Culture of bronchoalveolar lavage fluid was also performed in infants that were ventilated.

\section{Laboratory methods}

A $1 \mathrm{~mL}$ blood sample was drawn from the peripheral vein for CRP measurements. CRP was measured on the same sample, using our central laboratory method (CRP-Lab) and two different bedside tests, each requiring $\sim 3 \mathrm{~min}$ to obtain the result. Our central laboratory measures CRP by the 
CardioPhase hsCRP on BN II System (Dade Behring, Newark, $\mathrm{NJ}$, USA) which is a particle enhanced immunoturbidimetric method requiring $1 \mathrm{~mL}$ of whole blood. Due to organizational considerations, our central laboratory gives us the result in $\sim 24 \mathrm{~h}$, even though this method requires only $6 \mathrm{~min}$ to perform. The result is evaluated by comparison to a standard with a known CRP concentration. The assigned value of CRP in N Rheumatology Standard SL is traceable to the international reference preparation BCR-CRM 470 (12). The lower limit of detection for CRP for our laboratory is $0.175 \mathrm{mg} / \mathrm{L}$. The Quick-Read CRP (CRP-Q; Orion Diagnostic, Espoo, Finland) is an immunoturbidometric assay based on microparticles coated with anti-human CRP. This method measures the change in turbidity of the solution caused by the reaction of the particles and CRP in the sample. It requires $20 \mu \mathrm{L}$ of whole blood and provides results in $2 \mathrm{~min}$, with an analytical measurement range of 8-160 mg/L. The NycoCard CRP-single test (CRP-N; Axis-Shield, Oslo, Norway) is a solid phase, sandwich-format, immunometric assay requiring only $5 \mu \mathrm{L}$ of whole blood. In the test well of the device a membrane is coated with immobilized CRP-specific monoclonal antibodies. When the sample flows through the membrane, CRP is captured by the antibodies in a sandwich-type reaction. The membrane changes color in the presence of pathological concentrations of CRP. The instrument quantitatively measures the color intensity in 3 min with an analytical measurement range of $8-200 \mathrm{mg} / \mathrm{L}$. As recommended by the manufacturer, all results obtained with the two bedside assays were corrected for hematocrit values that deviated from $40 \%$, using a fixed table provided by the manufacturer. A coefficient of variation of $7 \%$ was observed at a CRP con- centration of $0.41 \mathrm{mg} / \mathrm{L}$ for the CRP-Lab, and at a CRP concentration of $12 \mathrm{mg} / \mathrm{L}$ for the bedside tests.

\section{Statistics}

Sensitivity, specificity, positive and negative predictive values were calculated comparing all the measurements obtained by the bedside tests (CRP-O Quick-Read test; CRP$\mathrm{N}$ NycoCard test) with those performed in the CRP-Lab. CRP values $\geq 10 \mathrm{mg} / \mathrm{L}$ were considered as positive for all three tests. Considering only positive CRP values, we evaluated the agreement of measurements between each bedside test and the central laboratory test using Passing-Bablok nonparametric regression. The regression equation was expressed with the $95 \%$ confidence interval $(\mathrm{Cl})$ for the estimates of the slope and intercept. The Bland-Altman plot was chosen to visualize the agreement between each bedside test and the CRP-Lab. We performed univariate linear regression to verify the possible influence of some factors on the difference between each of the methods investigated and the CRP-Lab. Variables included in the model were gestational age, birth weight, age and weight when sepsis was suspected, hematocrit and CRP values. The coefficient of determination $\left(r^{2}\right)$ was used to check for the goodness of fit. Only those variables with a $p<0.25$ were considered for multiple linear regression analysis. Statistical analyses were performed with Microsoft Excel 2003, SPSS for Windows rel. 17.0 (SPSS, Inc., Chicago, IL, USA) and Medcalc software rel. 9.3.7.0 (Medcalc, Mariakerke, Belgium). A $p<0.05$ was considered for statistical significance.

Table 1 Sensitivity, specificity, positive predictive value (PPV) and negative predictive value (NPV) for the two bedside tests, assessed in comparison with central laboratory CRP concentrations $\geq 10 \mathrm{mg} / \mathrm{L}$.

\begin{tabular}{|c|c|c|c|c|}
\hline & Sensitivity, \% & Specificity, \% & PPV, \% & NPV, \% \\
\hline Quick-Read CRP & 97.2 & 80.6 & 83.3 & 96.7 \\
\hline NycoCard CRP single test & 94.4 & 83.3 & 85.0 & 93.8 \\
\hline
\end{tabular}

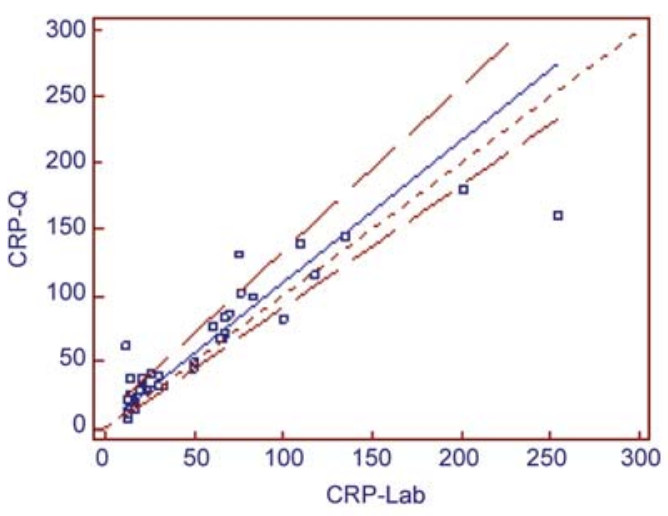

\begin{tabular}{|l|r|}
\hline $\mathrm{y}=1.0734 \mathrm{x}+1.8110$ \\
\hline Intercept & 1.8110 \\
\hline $95 \% \mathrm{Cl}$ & -2.2817 to 8.8861 \\
\hline Slope & 1.0734 \\
$95 \% \mathrm{Cl}$ & 0.9276 to 1.2439 \\
\hline
\end{tabular}

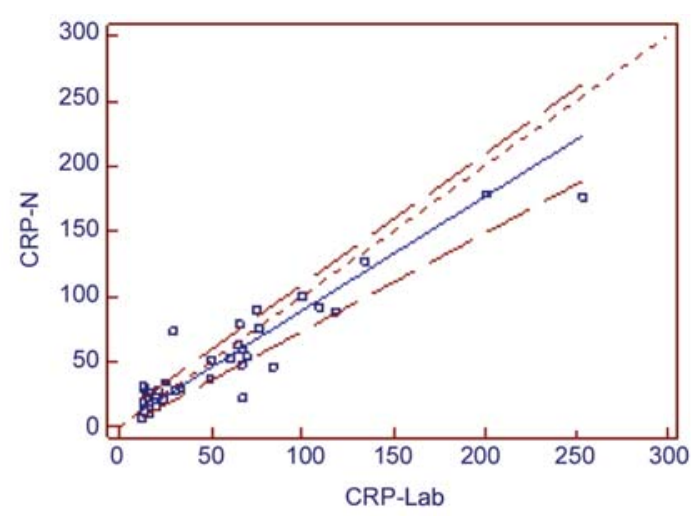

\begin{tabular}{|l|r|}
\hline$y=0.8759 x+0.9522$ & 0.9522 \\
\hline Intercept & -2.9140 to 8.0141 \\
\hline $95 \% \mathrm{Cl}$ & 0.8759 \\
\hline Slope & 0.7546 to 1.0048 \\
\hline $95 \% \mathrm{Cl}$ & \\
\hline
\end{tabular}

Figure 1 Passing-Bablok regression analysis between the central laboratory method and the two bedside tests. The analysis includes 36 samples with CRP-Lab concentrations $\geq 10 \mathrm{mg} / \mathrm{L}$. CRP values expressed as $\mathrm{mg} / \mathrm{L}$. The solid and dashed lines indicate the regression line and confidence interval for the regression line, respectively. CRP-Lab, central laboratory method; CRP-Q, Quick-Read test; CRP-N, NycoCard test. 


\section{Results}

A total of 72 blood samples were obtained for measurement of CRP concentrations. These samples were collected from 43 infants during 52 episodes of workup of suspected sepsis performed between 1 and 28 days of life (median 11, interquartile range 5-22 days). Gestational age and birth weight of the 43 infants were $33 \pm 5$ weeks (range 25-41 weeks) and $2250 \pm 950 \mathrm{~g}$ (range $510-4180 \mathrm{~g}$ ).

In the 36 samples with CRP-Lab concentrations $\geq 10 \mathrm{mg} / \mathrm{L}$ only one had CRP-Q $<10 \mathrm{mg} / \mathrm{L}$ and two had CRP-N $<10 \mathrm{mg} / \mathrm{L}$. In the 36 samples with CRP-Lab levels $<10 \mathrm{mg} / \mathrm{L}$, seven had a CRP-O $>10 \mathrm{mg} / \mathrm{L}$ and six had a CRP-N $>10 \mathrm{mg} / \mathrm{L}$. The specificity, sensitivity and predictive values are shown in Table 1.

Passing-Bablok regression yielded an equation of $y=1.0734 x+1.8110$ for CRP-O and $y=0.8759 x+$ 0.9522 for CRP-N (see Figure 1). The slope and the intercept were not significantly different from 1 and 0 , respectively. The Cusum test confirmed no significant deviation from linearity $(p>0.10)$. Bias for both assays vs. CRP-Lab was evaluated using Bland-Altman plots and is shown in Figure 2. The average bias values were determined to be $5.8 \mathrm{mg} / \mathrm{L}(95 \% \mathrm{Cl}-19$ to 13.4$)$ for CRP-O and $-5.7 \mathrm{mg} / \mathrm{L}(95 \% \mathrm{Cl}-12.6$ to 1.2$)$ for CRP-N. This means that Quick-Read and NycoCard had no statistically significant systematic proportional bias. The Bland-Altman plots also showed that the reliability of both bedside tests decreased with increases in CRP-Lab values. Univariate linear regression confirmed that the difference between each of the methods investigated and the CRP-Lab is affected by the highest CRP-Lab values only, and this was a bit more evident for CRP-N $\left(r^{2}=0.4693\right)$ than for CRP$\mathrm{Q}\left(r^{2}=0.3052\right)$. We did not perform multivariate regression analysis because no other variables reached $\mathrm{p}<0.25$ in the univariate analysis.

\section{Discussion}

Sepsis remains one of the main causes of neonatal morbidity and mortality and is particularly true for very low birth weight infants $(13,14)$. In the study published by Stoll and coworkers in 2002, of 6215 very low birth infants who survived beyond 3 days, $21 \%$ had one or more episodes of sepsis with a mortality rate of $18 \%$ (14). Antimicrobial treatment is often started on the basis of non-specific clinical signs because an early diagnosis can be crucial to optimize patient outcome. This attitude implies a widespread tendency for antibiotic abuse with the consequent risk of antimicrobial resistance. Between the several laboratory parameters that are predictive of sepsis, CRP has been thoroughly investigated because it can be detected within 6-12 $\mathrm{h}$ following the onset of the inflammatory process, and it peaks more quickly than other acute phase reactants $(15,16)$. However, the amount of blood and the time to obtain results from the central laboratory can constitute important limitations to serial CRP measurements in neonates with
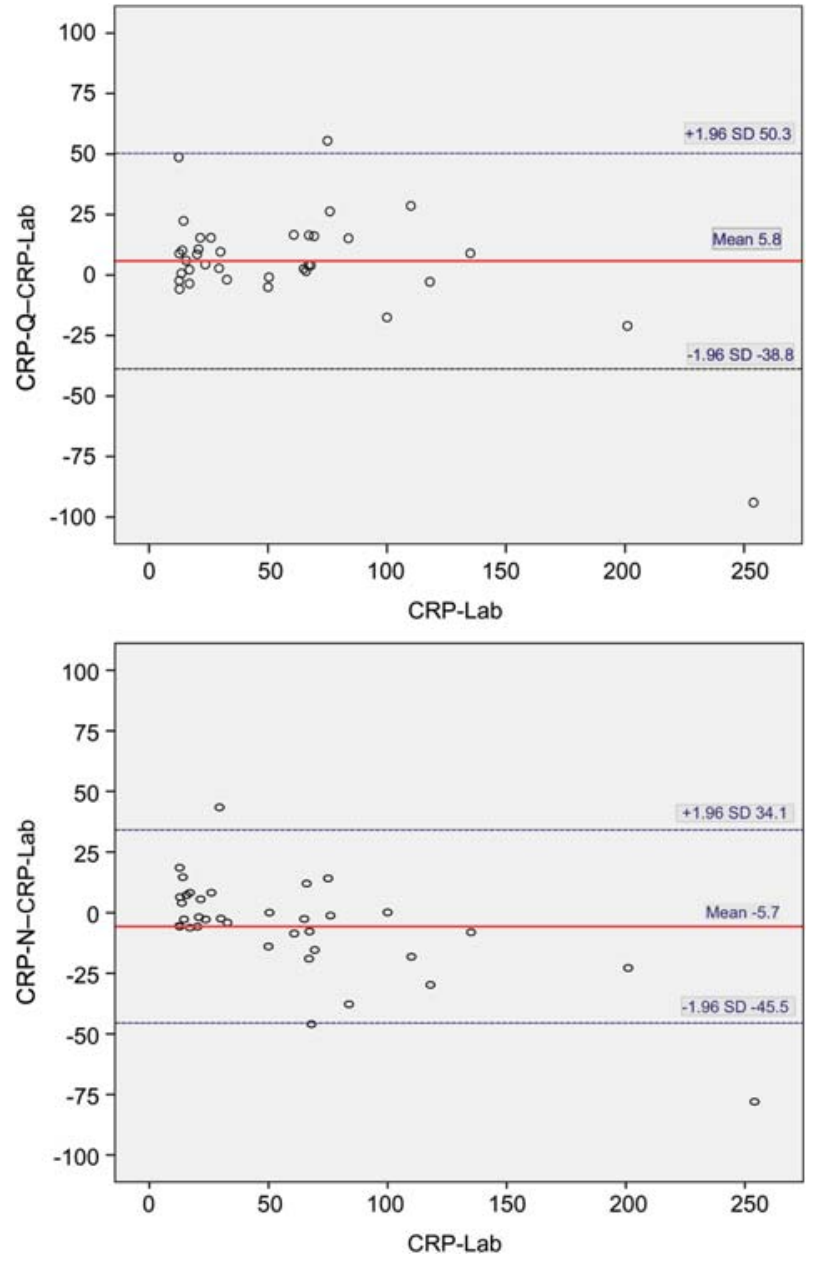

Figure 2 Bland-Altman plots between the CRP-Lab method and the two bedside tests.

The analysis includes 36 samples with CRP-Lab concentrations $\geq 10 \mathrm{mg} / \mathrm{L}$. CRP values expressed as $\mathrm{mg} / \mathrm{L}$. CRP-Lab, central laboratory method; CRP-Q, Quick-Read test; CRP-N, NycoCard test.

suspected sepsis. Despite the development of rapid quantitative bedside assays for CRP requiring an insignificant amount of blood, the short report by Makhoul and coworkers on late-onset sepsis is the only one published about their use in the neonatal period (11). Some authors studied the usefulness of CRP determinations in neonatal sepsis, but they did not use bedside tests $(4,8,17,18)$. Others studied bedside tests in pediatric patients, but not in neonates (19-22). For these reasons, we designed this prospective study to compare the diagnostic accuracy between two rapid bedside tests for CRP compared with a laboratory method and to provide information concerning their reliability in newborn infants.

Considering CRP values $\geq 10 \mathrm{mg} / \mathrm{L}$ to be positive, both bedside tests have good specificity (Quick-Read $80.5 \%$, NycoCard 83.3\%), and an even better sensitivity (Quick-Read 97.2\%, NycoCard 94.4\%), when compared with our CRP-Lab. The agreement of measurement with the central laboratory values as estimated by Passing-Bablok analysis is high for both the bedside tests, without significant differences between them. The slope was 1.0734 for Quick-Read and 
0.8759 for NycoCard. Both Passing-Bablok regression and Bland-Altman analysis showed that Quick-Read and NycoCard have no statistically significant systematic proportional bias. Univariate regression analysis showed that gestational age, birth weight, hematocrit and day of life have no influence on the agreement of measurement between the bedside tests and the central laboratory assay. The accuracy of measurements for both the bedside tests is affected only by very high CRP concentrations (>100 mg/L). This finding was more evident for the NycoCard than for the QuickRead test. Interestingly, this observation is in agreement with that of Cohen et al. (20) who found relevant quantitative discrepancies between the CRP-N and their CRP-Lab for CRP concentrations > $150 \mathrm{mg} / \mathrm{L}$. However, this limitation is of little clinical relevance considering that only four out of 72 of our study samples showed CRP concentrations $>100 \mathrm{mg} / \mathrm{L}$.

In conclusion, we provide evidence that both the Quick-Read test and the NycoCard test have excellent correlation with a validated CRP assay in newborn infants. They have high sensitivity and specificity, require a very small amount of blood, and are easy to use at the bedside of the patient. Also, they provide highly reliable results in $<5 \mathrm{~min}$. These characteristics allow them to be used for serial determinations of CRP concentrations in newborn infants, and can be of great help for clinicians for diagnosing and managing neonatal sepsis.

\section{Conflict of interest statement}

The authors disclaim any conflict of interest. The authors did not accept any funding or support from organizations that may in any way gain or lose financially from the results of our study. None of the authors has been ever employed by organizations that may in any way gain or lose financially from the results of this study.

\section{References}

1. Goldstein B, Giroir B, Randolph A, International Consensus Conference on Pediatric Sepsis. International pediatric sepsis consensus conference: definitions for sepsis and organ dysfunction in pediatrics. Pediatr Crit Care Med 2005;6:2-8.

2. Haque KN. Definitions of bloodstream infection in the newborn. Pediatr Crit Care Med 2005;6:S45-9.

3. Cohen J. The immunopathogenesis of sepsis. Nature 2002; 420:885-91.

4. Caldas JP, Marba ST, Blotta MH, Calil R, Morais SS, Oliveira RT. Accuracy of white blood cell count, $\mathrm{C}$-reactive protein, interleukin-6 and tumor necrosis facto alpha for diagnosing late neonatal sepsis. J Pediatr (Rio J) 2008; 84:536-42.

5. Arnon S, Litmanovitz I, Regev RH, Bauer S, Shainkin-Kestenbaum R, Dolfin T. Serum amyloid A: an early and accurate marker of neonatal early-onset sepsis. J Perinatol 2007;27:297-302.

6. Lopez Sastre JB, Solís DP, Serradilla VR, Colomer BF, Cotallo GD, Grupo de Hospitales Castrillo. Evaluation of procalcitonin for diagnosis of neonatal sepsis of vertical transmission. BMC Pediatr 2007 Feb 26;7:9. http//www. biomedcentral.com/1471-2431/7/9.

7. Turner D, Hammerman C, Rudensky B, Schlesinger Y, Schimmel M. The role of procalcitonin as a preditor of nosocomial sepsis in preterm infants. Acta Paediatrica 2006;95:1571-6.

8. Kordek A, Halasa M, Podraza W. Early detection of an early onset infection in the neonate based on measurements of procalcitonin and C-reactive protein concentrations in cord blood. Clin Chem Lab Med 2008;46:1143-8.

9. Rothenburger M, Markewitz A, Lenz T, Kaulbach HG, Marohl K, Kuhlmann WD, et al. Detection of acute phase response and infection: the role of procalcitonin and C-reactive protein. Clin Chem Lab Med 1999;37:275-9.

10. Roine I, Faingezicht I, Arguedas A, Herrera JF, Rodriguez F. Serial serum $\mathrm{C}$-reactive protein to monitor recovery from acute hematogenous osteomyelitis in children. Pediatr Infect Dis J 1995;14:40-4.

11. Makhoul IR, Smolkin T, Zinder O, Diamomd E, Tamir A, Sujov P. Fast bedside measurement of blood count and $\mathrm{C}$-reactive protein in neonate with suspected late-onset sepsis. Acta Paediatrica 2005;94:960-3.

12. Whicher JT, Ritchie RF, Johnson AM, Baudner $S$, Bienvenu J, Blirup-Jensen S, et al. New international reference preparation for proteins in human serum (RPPHS). Clin Chem 1994;40:934-8.

13. Kermorvant-Duchemin E, Laborie S, Rabilloud M, Lapillone A, Claris Q. Outcome and prognostic factors in neonates with septic shock. Pediatr Crit Care Med 2008;9: 186-91.

14. Stoll B, Hanesn N, Fanaroff A, Wright L, Carlo W, Ehrenkranz $R$, et al. Late-onset sepsis in very low birth weight neonates: the experience of the NICHD neonatal research network. Pediatrics 2002;110:285-91.

15. Philip AG, Mills PC. Use of C-reactive protein in minimizing antibiotic exposure: experience with infants initially admitted to a well-baby nursery. Pediatrics 2000; 106:E4.

16. Pulliam PN, Attia MW, Cronan KM. C-reactive protein in febrile children 1 to 36 months of age with clinically undetectable serious bacterial infection. Pediatrics 2001; 108:1275-9

17. Lannergard A, Larsson A, Friman G, Ewald U. Human serum amyloid $A$ and high sensitive $C$-reactive protein in preterm newborn infants with nosocomial infections. Acta Paediatr 2008;97:1061-5.

18. Makhoul IR, Yacoub A, Smolkin T, Sujov P, Kassis I, Sprecher $\mathrm{H}$. Values of C-reactive protein, procalcitonin, and Staphylococcus-specific PCR in neonatal late-onset sepsis. Acta Paediatrica 2006;95:1218-23.

19. Marcus N, Mor M, Amir L, Mimouni M, Waisman Y. Validity of the Quick-Read C-reactive protein test in the prediction of bacterial pneumonia in the pediatric emergency department. Eur J Emerg Med 2008;15:158-61.

20. Cohen R, Romain O, Levy C, Perreaux F, Decobert M, Hau I, et al. Impact de la protein C-reactive en micromethode sur la pris en charge des enfants febriles aux ugrences pediatriques en Ile-de-France. Archives de Pediatrie 2006;13:1566-71.

21. Esposito S, Tremolati E, Begliatti E, Bosis S, Gualtieri L, Principi N. Evaluation of a rapid bedside test for the quantitative determination of $\mathrm{C}$-reactive protein. Clin Chem Lab Med 2005;43:438-40.

22. Galetto-Lacour A, Zamora SA, Gervaix A. Bedside procalcitonin and $\mathrm{C}$-reactive protein in children with fever without localizing signs of infection seen in a referral center. Pediatrics 2003;112:1054-60. 